\title{
SPECIFITY OF HISTORICAL BUILDINGS AND BIM METHODOLOGIES. A FIRST EXPERIMENTATION FOR THE FEDERICO II HEADQUARTERS IN NAPLES.
}

\author{
R. Picone, L. Veronese *
}

Dept. of Architecture, University Federico II of Naples, Italy - renata.picone@unina.it, Luigi.veronese2@unina.it

KEY WORDS: BIM, Restoration, Knowledge, Enhancement, Heritage, Federico II, Naples

\section{ABSTRACT:}

The Building Information Modeling is today one of the most advanced data cataloging and processing systems aimed to the digital representation of physical and functional characteristics of an object. These prerogatives make possible to create a model containing not only the geometric-architectural data of the building, but also the properties of the materials and technical elements that compose it, the construction phases, as well as maintenance operations, locating and programming them over time. Such an approach implies, therefore, not only a change of instruments for the representation of Architecture, but above all a change of "mentality", in which the building is seen as a "unitary" organism with a synchronous vision between architectural form, structural elements, construction techniques, materials and installations. The experimentation here presented concerns the case of the university complex of Federico II of Naples along the axis of Via Mezzocannone. The urban palimpsest housing the monumental front of the building, designed by Eng. Pierpaolo Quaglia and Guglielmo Melisurgo at the end of the Nineteenth century, and incorporating ancient religious complexes built in the Fifteenth century, as the monasteries of Donnaromita and the Old Jesus; heterogeneous elements that allowed to explore on the field limits and the possibilities of interoperability of BIM in which still have ample possibilities for experimentation.

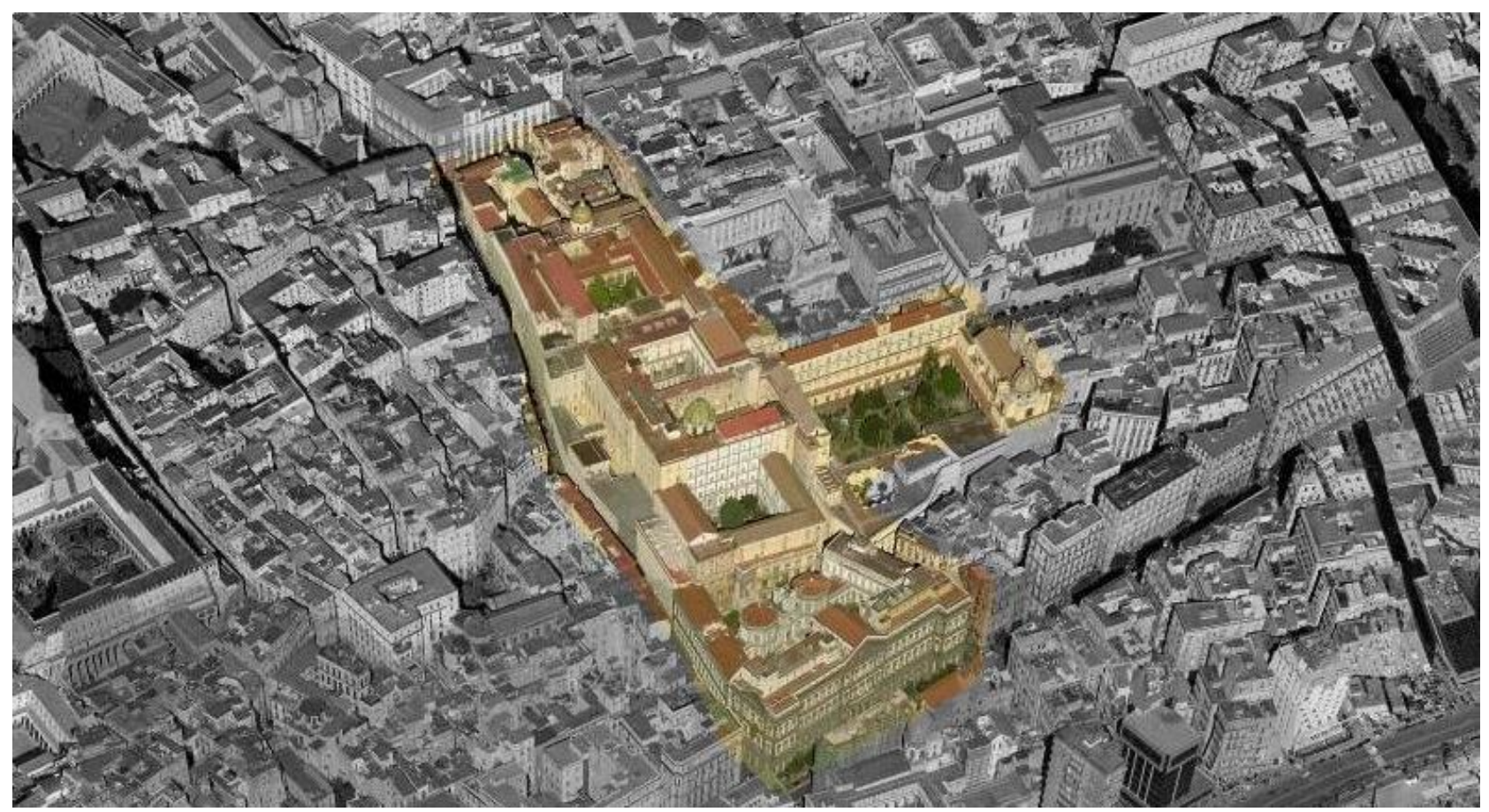

Figure 1. The Federico II settlement in the historic center of Naples. The aggregate of Mezzocannone with the front building built by Guglielmo Melisurgo and Pierpaolo Quaglia between the end of the nineteenth century and the beginning of the twentieth century.

\footnotetext{
* Corresponding author: E-mail addresses: renata.picone@unina.it (R. Picone), Luigi.veronese2@ unina.it (L. Veronese).

Although this contribution is the result of a shared work between the two authors, paragraphs 1, 4 are written by Renata Picone; paragraphs 2,3 by Luigi Veronese
} 


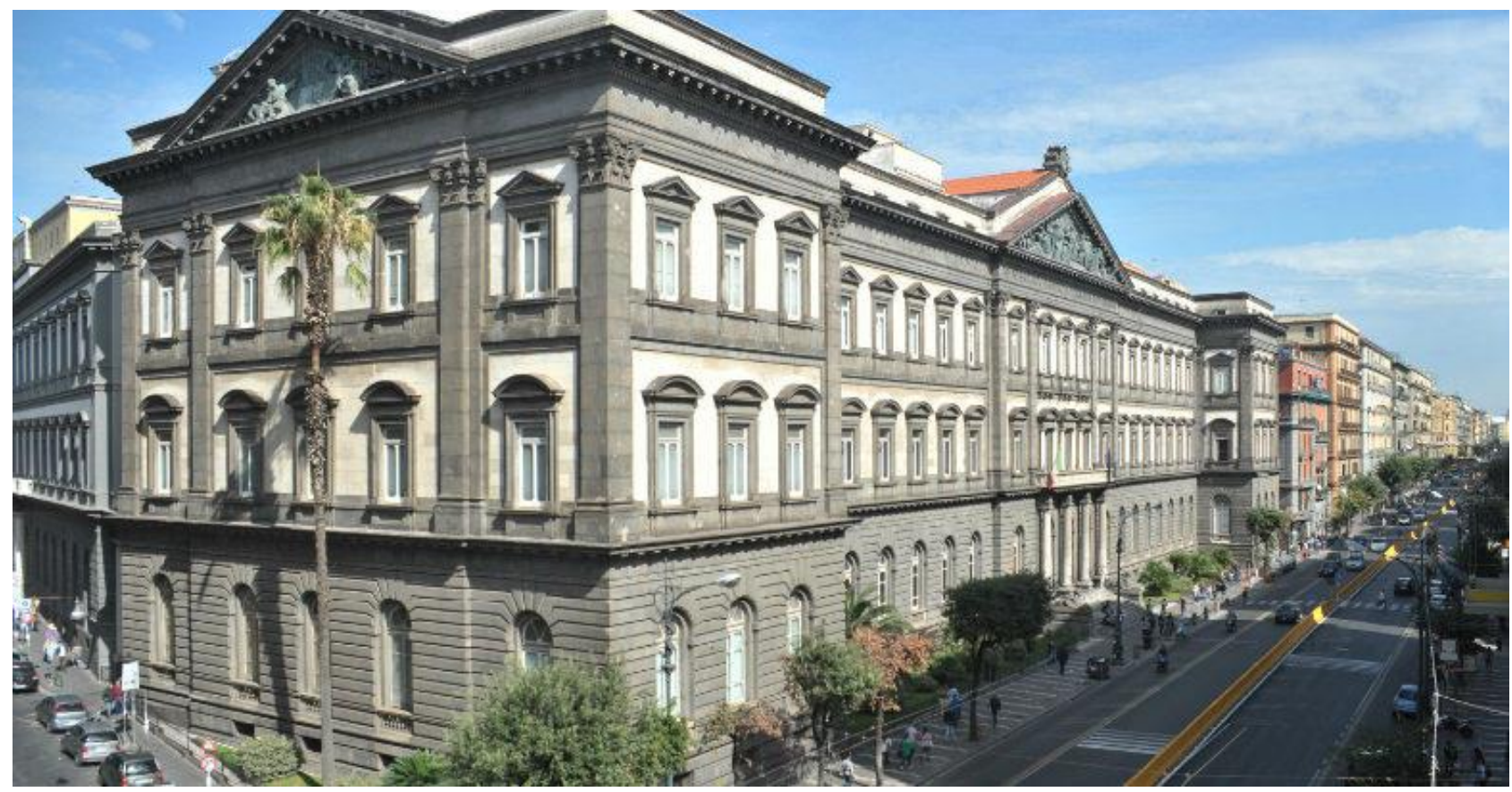

Figure 2. Naples. The front of the Federico II building on corso Umberto I (2016)

\section{INTRODUCTION}

The definition of which are the most suitable digital technologies for the documentation and management of historical built heritage data has long been the subject of a wide international debate, still open today, which seems to converge towards three-dimensional digital models capable of providing information stratified in the three dimensions. In this context, attention is shifted from the geometric model, obtained directly from the real artefact, to the creation of a three-dimensional database able to gather heterogeneous information derived from multidisciplinary fields that can meet the objective of ensuring a coherent, coordinated and planned conservation and enhancement of the built heritage (Della Torre 2014). Based on these objectives, is possible today identify two main digital "environments" that provide answers, with alternate advantages and disadvantages: the GIS (Geographical Information Systems) and the BIM. In extreme synthesis, while GIS information is necessary for the planning and management of roads, bridges, airports, railway networks and other infrastructures in the surrounding context, BIM information is essential for the design and construction of such facilities (Building Information Modeling) (Continenza, Giannangeli, Tata, Trizio 2016).

Regardless of the instrument chosen, in order to achieve an efficient management of information through a semantically enriched three-dimensional model it is necessary to consider three fundamental concepts: the creation of an ontology, the conceptualization of relationships and the identification of hierarchies. The first point is very important in the field of Conservation of the built heritage because the definition of ontologies capable of modelling an adequate process of study and restoration of historical architecture constitutes "a strategic line of research in a context increasingly oriented to perfecting the use of informatic equipment in the various disciplines. This modeling aims to overcome the simple constitution of databases (georeferenced or not) on historic buildings, rather wanting to offer a coherent support system to the investigation activities and to the planning itself and excluding, of course, the reductionist objective and misleading 'expert system' creation of an ontology" (Fiorani, Acierno 2017). Overall, the semantic enrichment of a three-dimensional digital model is the result of a cognitive and technical process that can adapt to one tool or another depending on the specific needs of the case, remembering that both environments are concerned with providing "spatial information".

BIM is first of all a 3D digital representation of an architecture with its characteristics related to geometry, materials and techniques. It consists of intelligent building components or characteristics of environments which includes data attributes and parametric rules for each object. This database must necessarily include a fourth dimension, the temporal one, linked to the life cycle of the asset and its scheduled maintenance over time. And it's possible even to talk about a fifth dimension related to the cost of the whole project (Della Torre et al. 2017). Trough the BIM technologies is possible to create a model of the real building able to integrate several information in an internalized system. This is a completely different from Computer Aided Design (CAD), that gets the information needed through external sources. It is noted that "a BIM model contains the buildings actual constructions and assemblies rather than a two-dimensional representation of the building that is commonly found in CAD-based drawings". The BIM technology provides much more advantages than CAD by being able to manage information, not just graphics.

BIM starts from the initial design and during the construction phase is used as a source of information. All information is incorporated in a model and thus can be studied securing valuable time and cost benefits. The model becomes absolutely comprehensible from all individuals that participate in its construction while at the same time provides the possibility of important utilities during building life-cycle (Brumana et al., 2013).

The developed virtual model provides an accurate overall picture to the project team (architects, civil engineers, surveyors, mechanical engineers, contractors, conservators, etc.). One of the most important BIM's characteristics is the 
prevision of a reliable basis for timely and quick decisions, helping the involved personnel to increase quality and productivity in the design but also during project operation. Since, BIM has greatly evolved in the recent years by providing high quality information in order to enable interoperability among diverse information systems the technology help to significantly reduce defects and risks in all stages of a project.

Many are the basic capabilities of BIM, with the most important of them aiming to develop the strategy of building project design, construction and maintenance management; ensure integration management of graphical and informational data flows, combine the graphical interface with the information flows and process descriptions; transform individual executors into teams and decentralise tools into complex solutions, this leading to individual tasks being implemented as complex processes; perform life cycle operations of a construction project more effective, faster and with lower cost (Popov et al., 2010).

BIM has been a growing development within the past decade in the field of cultural heritage documentation, paving the way towards a future in the virtually built environment. Many architects, archaeologists, conservationists, engineers regard BIM as a disruptive force, changing the way professionals can document and manage a historical monument.

The plug-in HBIM is a library of parametric objects that created from historic data. Furthermore, it is a system for mapping the parametric objects onto a point cloud and the survey image data. The HBIM process is started with distant collection of survey data using terrestrial laser scanning or digital photogrammetric modelling.

In building parametric objects, the problem of file format and exchange of data has been overcome by using Geometric Description Language (GDL). The scripting in GDL allows for sharing and editing of the parametric objects at different levels (Fiorani, Acierno, 2017).

The use of historic data introduces the opportunity to develop detail behind the object's surface concerning its methods of construction and material composition. In the last stage of the HBIM process, the libraries of parametric objects are mapped onto the point cloud and image survey data using a platform of cross software management. Full engineering orthographic drawings and 3D models can be automatically produced from the HBIM (S. Logothetis, A. Delinasiou, E. Stylianidis 2016).

If the processes of Building Information Modelling represent a winning way of approaching the integrated design of the new for the professional world, the use of BIM for the management of historical architecture becomes instead a strategic objective to be pursued. Since the potentialities expressed by the BIM are evident, in the case of historical contexts with a significant informative heritage (just think of the data deriving from the direct and instrumental survey, archive documents and drawings, historical photos, results of diagnostic campaigns, documentation of restoration, etc.), the international scientific community has begun to deal with the application of this to historical buildings and the archaeology of the building for some years, modifying the acronym in HBIM, or Historic Building Information Modelling. The substantial difference between the two processes lies substantially in the type of information that the two types of digital models preserve: the BIM process, through the different three-dimensional models, coordinates the professional figures that participate in the design integrated (architects, installers, structural engineers, etc.) also planning the timing and methods of organization and construction of the site. The HBIM process, which instead dwells on the phase of geometric, material and historical knowledge of the building, through the survey, the definition of the type and state of conservation of the materials, represents a three-dimensional repository mainly oriented to the documentation of the asset and to the planning of conscious restoration interventions.

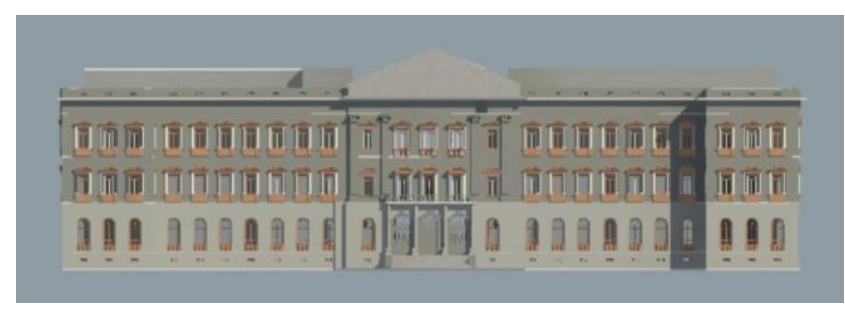

Figure 3. Naples Front of the Federico II building on corso Umberto I. 3D model (2018)

\section{THE CENTRAL SEAT OF THE UNIVERSITY OF NAPLES FEDERICO II}

The architectural aggregate, along via Mezzocannone, which today constitutes the central seat of the University of Naples Federico II, began to form in the mid-sixteenth century after the construction of the convent of the Gesù, by the Jesuits. These arrived in Naples in 1551, under the guidance of Alfonso Salmerone, and occupied the palace of Giantommaso Carafa in 1554 , which stood in the north area of the present church of the Gesù Vecchio. Here they arranged four classrooms, their home and a chapel, built in the ancient cellar. Immediately, however, they felt the need to build a new temple with annexed rooms for schools and already in March 1557 work on the church began. In this period the adjacent house of Giovanna Cominata was also purchased, which was used as a residence for the religious In 1558 a project was drawn up to enlarge the entire complex which included the construction of seventy rooms and ten classrooms (Buccaro 1993). The new factory was completed in 1566 and also included a new church, no longer existing today, of which traces have recently been found in the section of Via Paladino opposite the church of Monteverginella, as can be seen from the view of Lafrery (1566). In the same map is also possible to see a curving road - the ancient vico Mezzocannone - which from the homonymous street bifurcates on one side towards San Pietro a Fusariello, on the other towards San Marcellino: it is a path that existed until the vast interventions of mid-seventeenth century, along which, as Celano recalls, features of the Greek walls of Neapolis insisted (Alisio 1966).

The Jesuit architect Giuseppe Valeriano, who arrived in Naples in 1582 for the transformation of the Sanseverino palace into the church of the Gesù Nuovo, with the creation of the annexed Casa Professa conceived in 1584 a vast idea for the Collegio Massimo in Mezzocannone, which also included the acquisition of the convent of Donnaromita to reach the lower decuman towards the north. But from Rome it was immediately pointed out to Valeriano how the situation was different from that of the Collegio Romano. So, after the refusal by the nuns of Donnaromita, in 1584, to sell their monastery, the drawings of Valeriano were archived until 1596, when a new, more realistic idea was elaborated by the architect; this time he took into account the purchase by the Fathers of some downstream factories, including the creation of a public square (Buccaro 1993).

The courtyard designed by Valeriano was built in 1632 . The new church was built between 1608 and 1624 based on a design by another Jesuit architect, Pietro Provedi, in compliance with the most rigorous counter-reform canons. The schoolyard and 
the church were brought forward under the direction of the Provedi until 1623, the year of his death. The courtyard is one of the most characteristic examples of Jesuit school buildings, such as the Collegio Romano and those of Brera, Messina and Palermo. It is probable that also in the drawing of the Provedi, on the basis of the previous idea of Valeriano, the area on which the new buildings of the religious house downstream of the church would have risen was indicated. After 1656, based on a design by Cosimo Fanzago, the new staircase connecting the church with the Jesuit oratory was built, with the body to be used for seclusion (Fratta 2004).

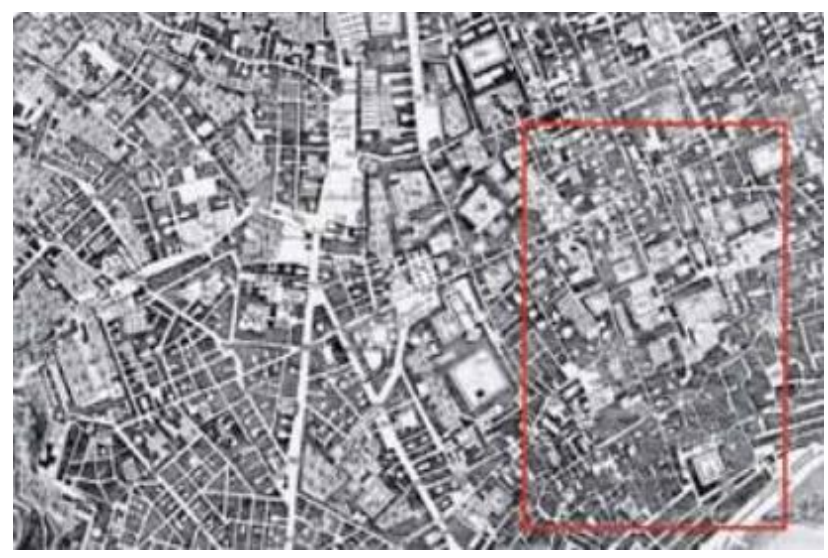

Figure 4. Duca di Noja. Map of Naples 1775

The new factories facing Via Mezzocannone were undertaken in 1680 on a design by Dionisio Lazzari: thus the "bislungo" courtyard was built, with the rich garden, on which the classrooms of the construction of the Valeriano appeared on one side, on the other, through the long arcade, new service environments, such as the «spetiaria» and the archive. In continuation of these factories, the first enclosure was created, leaning against the southern flank of the church, and the orthogonal arm, welcoming the large library, the pharmacy and the new refectory, the latter decorated with stuccoes by Lazzari himself. In the view of Petrini (1748) the "bislong" courtyard and the refectory wing are indicated for the first time, though with a certain approximation in proportions, while the new enclosure body is present on the southern side of the church. On the other hand, the last two arms closing the new courtyard welcoming the «citrus garden», nor the carriage ramps up to the road of the Sedile di Porto, now completed, do not appear, although they are being completed at that date (Pugliano 2007). The Fathers had thus obtained for their complex - which carried out the dual function of public school and college, and housed the numerous Jesuit congregations - an organic arrangement, also detaching their insula from the adjacent buildings and connecting it quickly, through new ramps continuously with vico del Salvatore (today's via Paladino), with the area below the marina, rich in traffic and commerce.

With "prammatiche" of 1768 and 1770 the Jesuits were expelled from the kingdom and the buildings, with the new name of "Casa del Salvatore", were destined for public schools. Only in 1777 the University was moved there from the Palazzo degli Studi, that became the museum of the Farnese collection. The buildings were included between vico Mezzocannone and via del Salvatore (later via G. Paladino), and between the vico of the University (today via G. Orilia) and vico S. Angiolillo. Starting from 1801 the hall on the third floor of the eighteenthcentury courtyard, already used as a Jesuit library, housed the Museum of Mineralogy, founded by Ferdinand IV. The following year, with the first restoration, the Jesuits resumed possession of their building which, however, they had to abandon again in 1806, by order of Giuseppe Bonaparte. In the Jesuit complex the University was then rearranged, which was divided into the five main faculties - Law, Theology, Medicine, Philosophy and Natural Sciences - arranged in the rooms adjacent to the seventeenth-century courtyard. Around 1836-37, on the occasion of the creation of the Museum of Zoology by the architects R. Cappelli and C. Diversi, the "citrus garden", whose space, gave life to the current court, was cut down; on this occasion the openings on the ground floor were created along the sides of the basin and the connecting staircase of the new level with the fanzaghiano staircase was also built.

Since 1886, having drawn up the executive plan for the Risanamento of the city by the Technical Division of the Municipality, according to the idea of the chief engineer Adolfo Giambarba, among other things, an extension of Via Mezzocannone was deemed necessary for a direct communication of the Rettifilo with Piazza San Domenico. The intervention, based on the cutting of the western front of the artery, will be performed over several decades, ending only in 1922 with the cut of Palazzo Casacalenda, facing the square; in the following years, as we shall see, the facade of the entire university complex will be redesigned. Still in the area of rehabilitation there is a general arrangement and expansion of the university complex, lacking in equipment and inadequate for a student population practically doubled from 1875 to 1886 . In the project drafted by engineers Guglielmo Melisurgo and Pier Paolo Quaglia between 1893 and 1896 was planned, together with a massive intervention on the former convents of Caponapoli, to be assigned to university clinics, the restructuring of the former Jesuit college (with consequent functional redistribution) and the construction downstream, in the area of St. Peter in Fusariello, of three new buildings in which the Rectorate, the Faculties of Letters and Jurisprudence and the Institutes of Chemistry and Physics would have found a place (Alisio 1981).

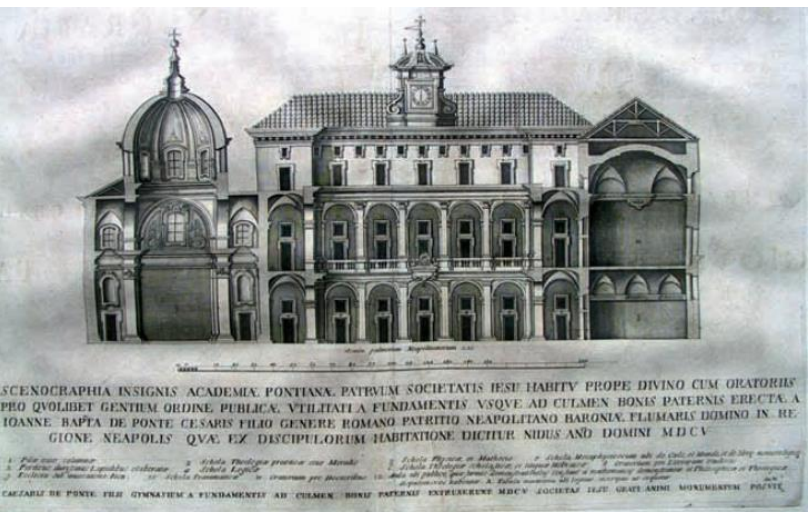

Figure 5. Section of the Collegio Massimo of the Jesuits (Pugliano 2007)

For the new nineteenth-century buildings of the University, the executive drawings of the Risanamento plan only envisaged private building, on the lots corresponding to this area along the Rettifilo; but early in 1886 the rector Trinchese asked for a vast intervention for the estension of the ancient university complex, approved by the municipal Council. In addition to renovating the Jesuit buildings, it was necessary to create new offices for the administrative offices and for the Faculties of Letters and Law, and finally to equip the Faculties of Sciences of the 
chemistry and physics cabinets, as the students were forced to follow the exercises at the laboratories of the Genoese high school. The formation of a consortium was then promoted between the southern provinces that, with the help of the government, financed the operation, and starting from 1991 was drawn up by the engineer Melisurgo, at his own expense, a relative program, as it already was mentioned, the restructuring and expansion of the existing site, as well as a massive intervention on the other former convents assigned to the University (Alisio 1981).

After the request, formulated by the "Society for Reclamation" to Melisurgo and remained unsuccessful, concerning the transfer of the general plan, in 1892 he was joined to the engineer Pier Paolo Quaglia, director of the Art Office of the same Company, who would have collaborated in the deepening of the project and in the drafting of the executive studies. Downstream of the former Jesuit college, instead of the isolated San Pietro a Fusariello, new factories were to be built near the Rettifilo. The general papers were presented in April 1893 to the Martini minister.

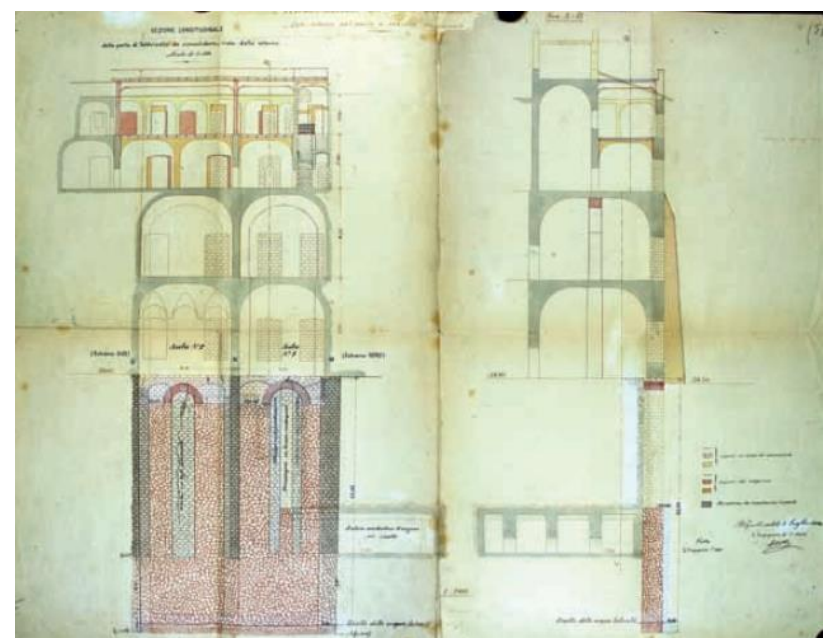

Figure 6. Progetto pel consolidamento dell'ala nord-ovest del cortile principale del Palazzo Universitario in Napoli, colla ricostruzione del muro occidentale, Napoli 2 luglio 1904

(Pugliano 2007)

The main factory facing the "Corso d'Italia", having a surface of 2590 square meters and a front of about 120 meters, would have developed on three levels, with a strongly protruding central body, as well as the extreme parts, larger than to those then realized. Above the ashlar basement, the façade approved in 1896 shows two rows of arched openings closed by giant Corinthian pilasters: the central area and the two wings appear crowned with pediments while the two intermediate ones present a continuous attic; finally, a tall square-shaped iron and glass dome, clearly inspired by Antonelli, dominates the building. The necessary isolation of the road is ensured, in addition to the large central staircase, by a gate in line with the heads, giving up the two inclined planes for access to the portico indicated in the general perspective view of the 94 project; the entrance conceived as a triumphal arch, with the coats of arms of the nation, the municipality and the consortium provinces, appears dominated by a Corinthian loggia corresponding to the great hall. The criticisms made by numerous men of culture in the aftermath of the exhibition of the graphics in the University Library raised a strong protest movement, headed by the Cross, against the planned destruction of many former convents for the arrangement of the new clinics in Caponapoli. To the sumptuous formal apparatus adopted in the facades of the new university complex, all pervaded by Mannerist and Baroque influences, corresponded within a rather fragmentary articulation of the bodies of the factory: here a greater degree of syntactic and compositional freedom was granted to the designers precisely because of the absence of any need for monumentality (Alisio 1981).

The aula magna, served by the two main staircases, would have occupied the entire depth of the building; it would have been equipped with upper stands and covered, towards the courtyard, with a "cap" also unrealized. In the executives of 1896 the buildings appear to be very different from those later executed, equipped with different $\mathrm{C}$-shaped plants with only two levels above ground, they show particular stereometric characteristics, with semicircular bodies placed in several points with prismatic volumes, as well as curved angular shapes; in particular, the main classrooms would have had an original lobed plan, with glazed canopies and internal amphitheater structures 237 . The program to restructure the ancient complex of the Savior is also far-reaching. The long central path would have penetrated inside the factory through a portico connecting the fanzaghiano staircase, then creating another stairway to serve the new cabinets of Mineralogy, Zoology and Geology, and proceeding with the restructuring of numerous other rooms. Although the first stone of the building was laid by the Prince of Naples on 28 October 1896, at the beginning of the following year the problem of the façade was re-proposed, for which the designers themselves disagreed. The Minister of Public Works entrusted a commission, formed by Giuseppe Sacconi, Guglielmo Calderoni and Lorenzo Schioppa, with the task of expressing his own judgment in this regard.

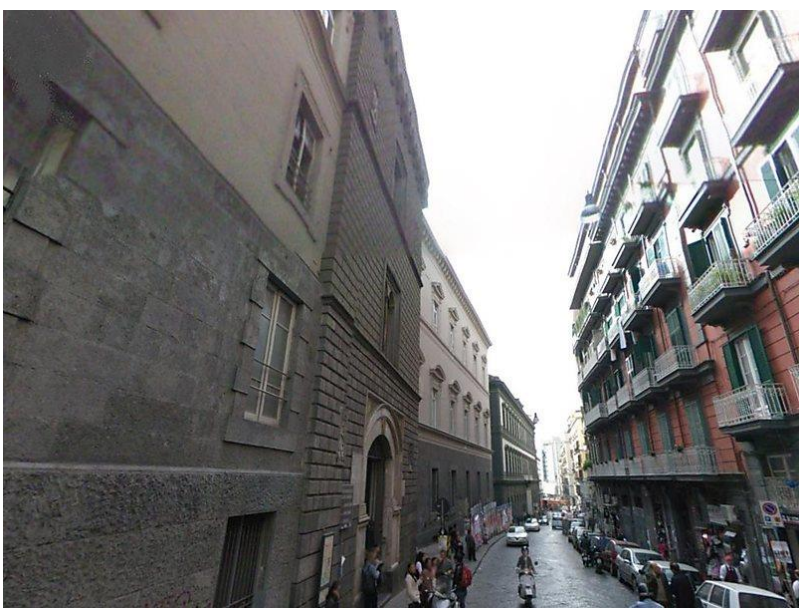

Figure 9. Napoli. Via Mezzocannone (2018)

The Melisurgo and Quaglia project, examined by the Public Works Council on 2 June 1897, was corrected on some nonsubstantial points. The renovations will be completed by 1908 together with those relating to the construction of new buildings towards the "Rettifilo". Between 1926 and '29 the vertical of the current entrance to n. 8, re-using the portal of the fifteenthcentury palace of Fabrizio Colonna, already present in Via Mezzocannone which was inserted in a new façade with late Gothic forms; finally, in the same building the staircase was created and the elevator was brought to the lower level of the new entrance hall.

The three-storey building at the former great hall was rearranged and, next to it, a new large hall was built with three 
rooms, one on each floor, destined for the Ornamentation and Architecture Schools, the Militia Command University and the Society of Naturalists. The fifth on via Mezzocannone, as it emerged from the interventions examined above, was conceived in continuity with the front of the former Engineering School: it came to connote the artery in the aftermath of the cut performed on the western side, opposing to a 'anonymous building curtain forms typical of a late eclecticism - from the neo-renaissance to neo-Mannerism - and materials (stone and marble) suitable to represent the public institution in a much poorer and sloppy context. By 1930 a new staircase was built in the body on Via Orilia, which was then renovated. In addition, the adjacent terrace overlooking the courtyard of the statues, as well as those on the opposite side, were raised with two floors of the factory. A positive restoration was carried out in 1938, when the courtyard of the statues was freed from the previous attintature of the Vesuvian stone parts (Fratta 2004).

After World War II, numerous interventions led to further transformations, especially due to the internal changes required by the adaptation of the premises to the needs of the institutes and university departments. In the Sixties new alterations were carried out under the direction of the Civil Engineers: the ancient refectory of the Jesuits, for example, is completely disfigured due to the presence of a laboratory of exercises of the Department of Chemistry; numerous superelevations and additions have also affected both courtyards, distorting almost entirely the original covering solutions. Among the parts of the building that have preserved their primitive character, in addition to the monumental courtyard and the church, the ancient library (now home to the Museum of Mineralogy), the Zoology museum, and some rooms of the University Library are to be included. of the Academy of Sciences, Letters and Arts.

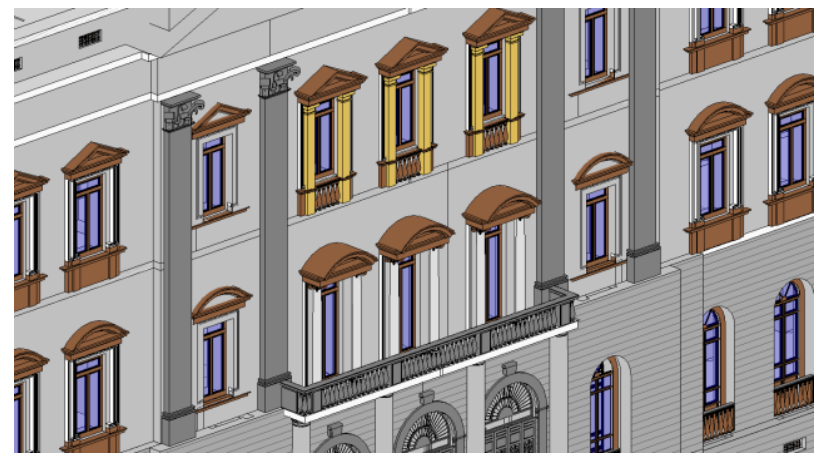

Figure 7. Naples Front of the Federico II building on corso Umberto I. 3D model (2018)

\section{THE DIDACTIC-APPLICATIVE EXPERIMENTATION}

The didactic-applicative experimentation has been started in concert with the University, which has made available a wide relief campaign made with 3D laser scanners.

Specifically, a restoration and maintenance tool has been implemented which, based on a BIM model of the building, allows interaction with a specially structured external database. Additional features have also been developed that allow easy consultation of data and simple use of the system: interfaces for data entry, editing, consultation and querying, theming, creation of ad hoc documents such as degradation maps, etc. The system presented here was intended as an information system on the architectural scale. Thanks to the database, it allows to archive and correctly query all the data necessary for the description of the building. This database has been structured to be interoperable with the main BIM software and can also be consulted via web applications. In the current state of research, the interaction with Autodesk's Revit platform was investigated. In fact, Revit today represents the most widely used tool in BIM and provides numerous APIs (Application Programming Interface) and SDK (Software Development Kit) that make it easy to program.

The first phase of the experiment has deepened the historical and archival data relating to the Mezzocannone factory.

We then proceeded with the modelling of the architectural aggregate taking particular care of the relief and definition of the 3D model in order to account for all the architectural features of the building including the multiform variety of existing forms of degradation. For this model, a 3D drawing was used based on the laser scanner survey provided by the University and the related point cloud.

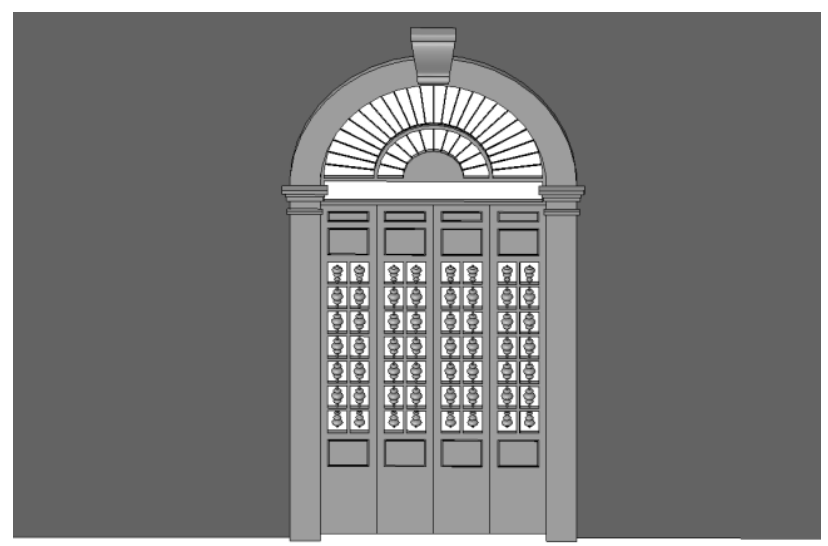

Figure 8. Naples Federico II building. 3D model of the main door (2018)

On the external surfaces of the model, in particular, the "straightened" photographic images have been loaded with appropriate software.

Once the model was completed, we moved on to a more analytical phase of the process, in which we began to think about how and where to allocate information, both technical and historical, that we wanted to deposit within the model. In this phase of the research the problem has therefore been posed of the coding methods to be adopted for the classification of the technical elements, according to a hierarchical and gradual criterion which would also depend on the system of organization and aggregation of the information to be associated to the individual elements of the building system. It was immediately clear that, depending on the decomposition system that we would have decided to use, the construction methods of the initial model could have undergone an important revision, not only for the level of detail to be achieved with the representation, but also for the possible need to break down the same object into several univocally identified elements.

It was therefore decided to proceed according to a dual logic of decomposition, adding to a technological-functional coding criterion of the building system, a further criterion of materialsurface type; this choice despite being aware of the known limitations and criticalities related to the System, was the result of a long phase of analysis of the problem and is closely related to the specific objectives of the research.

Once the modelling phase is completed, the data allocation phase is started. 
In the first instance, the contents to be transferred to the information system are defined and the various forms to be associated with the mayors are therefore defined; in particular they have been purposely built regarding the historicalarchitectural field, the material aspects and the degradation conditions of the surfaces, the interventions foreseen by the restoration project and the future controls necessary to guarantee the long-term conservation.

The sperimentation has provided satisfactory results in the parts of the building more homogeneous, as in the case of the front on Corso Umberto I, built in a unified manner in 1896. Here the partitions, the finishes and the decorative elements, realized with clearly identifiable materials and techniques, have allowed to define a BIM model more faithful to the actual state. On the other hand, the results of the application of the model to the most stratified portions of the building, in which the historical transformations have produced a complex palimpsest of forms, material living levels and construction techniques, appear more problematic. In this case, inevitably, the computer representation is affected by the limits of physical knowledge of the building, offering interesting insights for further study.

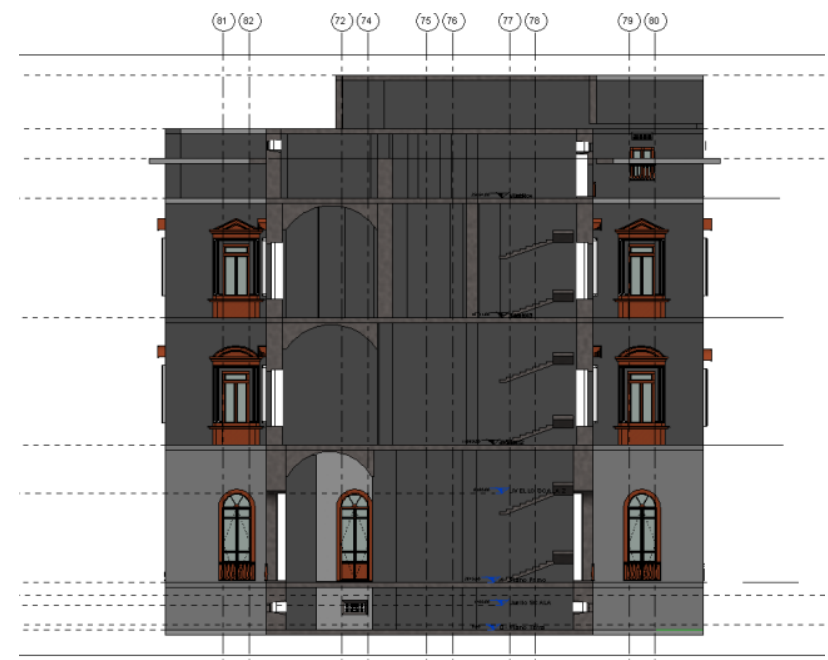

Figure 10 Naples Section of the Federico II building on the main staircase. 3D model (2018)

\section{CONCLUSIONS}

BIM must be considered a methodological approach that allows to manage all phases of the life of a building in a coherent and coordinated way, 1 so that it can also be applied to existing buildings (Della Torre et al., 2017).

In the field of cultural heritage, the use of BIM is very limited and is still the prerogative of universities and research centers, while in the professional field the applications are still small and linked to very specific areas. The reasons for this imbalance can be traced back to the difficulties linked to the implementation of a BIM model of the existing. In fact, shared regulations and standardized workflows are lacking, but above all there are considerable difficulties both in the modeling phases and in the retrieval of the thematic information: uncertainties on construction techniques, a complex succession of construction and reconstruction phases, presence of elements that cannot be standardized nor referable to predefined libraries, presence of deformations and irregularities, etc. Despite these difficulties, as demonstrated by the literature in this regard, the use of BIM for the documentation and management of historical building heritage presents innumerable advantages: coherent and coordinated management of documents relating to different temporal phases (Brumana et al., 2013), single access point for all data, support for technical analysis, support for scheduling maintenance interventions, promoting cultural heritage, by sharing the model on the web or the realization of virtual or augmented reality applications (Fiorani, Acierno, 2017). It is therefore desirable that research projects are set up to implement this technology with these aims, contributing to the solution of the numerous problems still present.

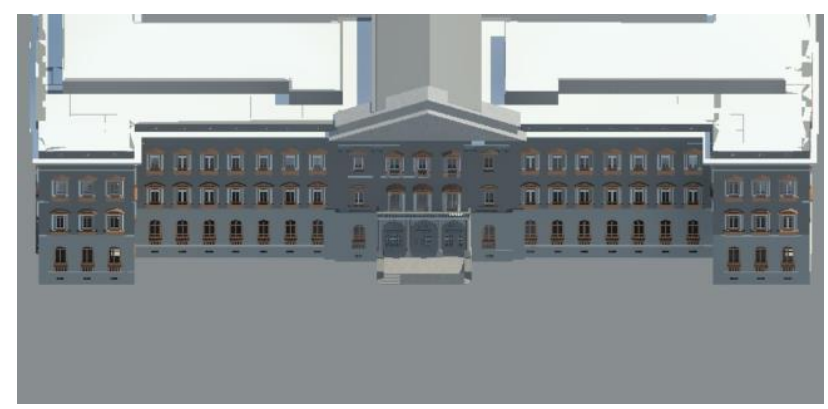

Figure 11. Naples Front of the Federico II building on corso Umberto I. 3D model (2018)

The experimentation here described has allowed us to test on an architectural scale, not without difficulty, what has already been experimented previously with three-dimensional Architectural Information Systems (SIArch 3D), or the possibility of topologically connecting heterogeneous data to a 3D model representative of a historic building. Although the results of the experimentation are still to be verified as, as anticipated, this is still in progress, it can be said that, compared to similar experiments conducted previously, the modeling procedure is little affected by the problems related to interoperability between formats found with 3D GIS. As in that case also here it can be seen that the major problems faced derive from the use of software created for different purposes (in the case of BIM the design of new building bodies rather than the recovery and management of existing built heritage). Therefore, the typical irregularity of archaeological contexts or historic buildings is not compatible with the automatic nature of software functions and with the orientation oriented towards those features of geometric regularity that characterize contemporary architecture and that make it impossible to exploit the full potential of software related to seriality, equality of proportions, repetition making, in the case of historical contexts, the continuous use of manual procedures (implementation of ad hoc families) that lengthen the time of the procedure. Instead, the aspect linked to the fourth dimension of the semantic model is to be further investigated, meaning the temporal management of the asset, carried out through the planning of maintenance programs, the documentation of extraordinary interventions and all monitoring activities in a broad sense.

An overriding implementation of such an interoperable knowledge model can be developed, not only for the fase of the restoration, but also with an attention to prevention of the historic building, a key activity, whose lack often causes dramatic losses of the built heritage (Della Torre 2014).

\section{REFERENCES}

Alisio G. C. 1966, Napoli e il risanamento edilizio: recupero di una struttura urbana, ESI 
Alisio G. C. 1966. Il Gesù Vecchio a Napoli, in "Napoli nobilissima", n. s., V

Buccaro A., 1993. La sede centrale dell'Università di Napoli: iter progettuale e scelte di eclettismo architettonico. In: Fridericiana, vol. 4, pp. 107-123. Napoli: Casa Editrice Fausto Fiorentino.

Brumana, R., Oreni, D., Cuca, B., Binda, L., Condoleo, P., Triggiani, M., 2013. Strategy for integrated surveying techniques finalized to interpretive models in a byzantine church, Mesopotam, Albania. On publishing in International Journal of Architectural Heritage

Della Torre S., Mirarchi C., Pavan A., 2017. Il BIM per la conservazione rappresentare e gestire la conoscenza. ANANKE, vol. 80 , p. $108-115$

Della Torre S., 2014. La programmazione degli interventi: qualità, modello di gestione, riconoscimento delle esternalità positive. MATERIALI E STRUTTURE, vol. NS II, p. 107-117.

Continenza R., Giannangeli A., Trizio I., Tata A., 2016. HBIM per il progetto di restauro: l'esempio della chiesa di San Cipriano a Castelvecchio Calvisio (L'Aquila). DISEGNARECON, volume 9/ n. 16 - june 2016.

Fiorani D., Acierno M., 2017. CPM: un'ontologia per il restauro, in Ananke Speciale Geores, Settembre 2017.

Fiorani D., Acierno M., Cursi S., Simeone D., 2017. Architectural Heritage Knowledge Modelling: an OntologyBased Framework for Conservation Process. JOURNAL OF CULTURAL HERITAGE, pp. 124-133.

Fratta A. (a cura di) 2004. Il patrimonio architettonico dell'Ateneo Fridericiano" Arte Tipografica Editrice

Logothetis S., Delinasiou A., Stylianidis E., Building information modelling for cultural heritage: a review, ISPRS Annals of the Photogrammetry, Remote Sensing and Spatial Information Sciences, Volume II-5/W3, 2015

Murphy, M., McGovern, E., Pavia, S., 2009. Historic building information modelling (HBIM). Structural Survey 27 (4), 311327.

Popov, V., Juocevicius, V., Migilinskas, D., Ustinovichius, L., Mikalauskas, S., 2010. The use of A Virtual Building design and Construction model for developing an effective Project concept in 5D environment. Automation in construction 19(3), pp. $357-367$

Pugliano G., 2007. Per la storia della sede della Società Nazionale di Scienze, Lettere e Arti in Napoli. Atti Accademia Pontaniana, Napoli N.s., Vol. LVI (2007), pp. 265-316. 